\section{(6) OPEN ACCESS}

\title{
Epidemiology of occupational hypersensitivity pneumonitis; reports from the SWORD scheme in the UK from 1996 to 2015
}

\author{
C M Barber, ${ }^{1}$ R E Wiggans, ${ }^{1}$ M Carder, ${ }^{2}$ R Agius ${ }^{2}$
}

Health and Safety Laboratory, Centre for Workplace Health, Health and Safety Executive, Buxton, UK

${ }^{2}$ Centre for Occupational and Environmental Health, The University of Manchester, Manchester, UK

\section{Correspondence to} Dr C M Barber, Health and Safety Laboratory, Centre for Workplace Health, Health and Safety Executive, Harpur Hill, Buxton SK17 9JN, UK: Chris.barber2@sth.nhs.uk

Received 11 May 2016 Revised 13 July 2016 Accepted 2 August 2016 Published Online First 10 October 2016

\section{CrossMark}

To cite: Barber CM, Wiggans RE, Carder M et al. Occup Environ Med 2017;74:528-530.

\section{ABSTRACT}

Objective To estimate the reported incidence of occupational hypersensitivity pneumonitis (OHP) in the UK and to consider whether the pattern of attributed causation has changed over time.

Methods All cases of OHP reported to the SWORD scheme between January 1996 and December 2015 were classified into 1 of 10 categories of the suspected agent. Cases were grouped into four 5-year time periods to examine any changing pattern in incidence or suspected causation. For each time period, the annual incidence was calculated using the estimated number of reported cases and the working population of the UK.

Results Between 1996 and 2015, there were 202 actual cases of OHP reported to SWORD, equating to an estimated 818 cases, when adjusting for the sampling ratio. Over this period, the annual UK incidence was 1.4 per million workers. The mean (SD) age of reported cases was 52 (13) years, and cases were four-times more likely to be men than women. Over the study period, there was a fall in the proportion of cases reported to be due to agricultural exposures $(44-12 \%)$, and an increase in cases due to metalworking fluids (MWFs, 2-45\%).

Conclusions Over the last 20 years, the incidence of OHP in the UK has been $\sim 1-2$ cases per million workers per year. Working with water-based MWFs is now the most commonly suspected causative exposure for OHP cases reported to the SWORD scheme in the UK.

\section{INTRODUCTION}

Hypersensitivity pneumonitis (HP), also known as extrinsic allergic alveolitis, is a common form of interstitial lung disease, ${ }^{1}$ most commonly caused by domestic or workplace exposures. ${ }^{2}$ There is clear evidence that prognosis can be improved in HP if a cause can be identified, and further exposure avoided. ${ }^{3}$ Understanding the common sources of workplace exposure is therefore important to encourage earlier recommendations of antigen avoidance by clinicians managing this condition in patients of working age. National reporting schemes offer valuable data to assist in this. The aim of this study was to explore the most commonly suspected causes of occupational hypersensitivity pneumonitis (OHP) reported to the UK SWORD surveillance scheme ${ }^{4}$ and to consider whether these had changed over time.

\section{What this paper adds}

- Although hypersensitivity pneumonitis (HP) is a common form of interstitial lung disease internationally, little is known about the epidemiology of the condition.

- National reporting data offer a method of better understanding the occupational causes of this disease and examining trends in causation with time.

- The reported incidence of occupational HP in the UK is $\sim 1-2$ cases per million workers per year, which is similar to estimates for a limited number of other countries.

- Over the last 20 years, exposure to metalworking fluids has been the most frequently reported causative agent for cases of occupational HP reported to the SWORD scheme in the UK.

- Healthcare workers should be aware of the link between occupation and HP and take a systematic occupational history when assessing symptomatic workers.

\section{METHODS}

All cases of OHP reported to the SWORD scheme ${ }^{4}$ between January 1996 and December 2015 were classified into 1 of 10 categories by the suspected causative agent. Cases were grouped into four 5 -year time periods to examine any changing pattern in incidence or suspected causation. For each time period, the estimated annual incidence was calculated using the estimated number of reported cases and the working population of the UK at that time as documented by the Office for National Statistics (ONS). ${ }^{5}$

\section{RESULTS}

Between 1996 and 2015, there were 202 actual cases of OHP reported to SWORD, equating to an estimated 818 cases (allowing for differences in the reporting frequency of 'core' and 'sample' reporters). ${ }^{4}$ Over this period, the annual UK incidence was 1.4 per million workers (1.5 per million for each of the first three 5-year time periods, and 1.2 per million for 2011-2015). Reported cases were consistently more likely to be men than women with an overall ratio of $\sim 4: 1$, with $73-86 \%$ of cases being men in each 5 -year time period. The 
mean (SD) age of reported cases was 52 (13) years, which was not significantly different for men and women (52 vs 49 years, $\mathrm{p}=0.14$ ). Eighty-three per cent of reported cases were over the age of 40, and 20 of these were over the age of 65 (two-thirds of these were farmers).

During the period studied, the commonest suspected causes of $\mathrm{OHP}$ in the UK were exposures to metalworking fluids (MWFs, 35\%), farming (17\%) and birds (11\%). A wide range of occupations were reported to have been associated with OHP due to avian exposures, most commonly related to poultry farming and domestic bird breeding. Less commonly reported causes included contact with birds in pet shops, veterinary practices and bird sanctuaries. Twelve per cent of cases were attributed to other agents, and in 5\% of cases respiratory physicians were not able to identify the likely cause. The suspected causes of OHP between 1996 and 2015 per 5-year period are shown in figure 1.

\section{DISCUSSION}

This study has demonstrated that over the last 20 years, the overall incidence of OHP in the UK has been $\sim 1-2$ cases per million workers per year. Over this time period, reported cases were four times more likely to be men than woman. In terms of suspected causes, the proportion due to bird handling has remained relatively stable, whereas there has been a fall in reported cases due to agricultural exposures. In marked contrast, the number of cases due to water-based MWFs has risen dramatically, and this exposure is now the most commonly reported cause.

The limitations of estimating the incidence of work-related respiratory disease from the SWORD data, ${ }^{6}$ examining trends in incidence ${ }^{7}$ and comparing this with data from other national reporting schemes have been discussed in detail elsewhere. ${ }^{8}$ These relate to the potential underestimation of incidence rates as not all chest physicians participate in the SWORD scheme, the potential for reporter fatigue over time and differences in the design of national reporting schemes. The data used in this study are based on voluntary reporting, and the SWORD scheme does not record information as to how the diagnosis was confirmed or how the suspected agent was identified. The true incidence of OHP is unknown, but it is likely to vary between countries with different climates, types of industry, smoking prevalence and genetic factors. This study estimated the clinically reported UK incidence of OHP to be $\sim 1-2$ per million workers, which is lower than the 8 per million workers estimated for allergic occupational asthma (OA) over the same time period. The relative incidence of these allergic lung diseases in the UK is significantly different from other national reporting schemes, where 25-30 cases of $\mathrm{OA}$ have been reported for each case of $\mathrm{OHP}^{9-11}$ International comparisons are inherently difficult, ${ }^{8}$ and the reasons for this difference are not apparent from our study. It is clear however that the UK estimate of the incidence of OHP is within the 0.4-2.7 per million workers range that has been estimated by other reporting schemes from Australia, ${ }^{9}$ Catalonia, ${ }^{10}$ the Czech Republic, ${ }^{12}$ France and Germany. ${ }^{13}$ A higher estimate of 12.2 per million workers comes from the Finnish National Register, ${ }^{11}$ which may relate to the design of reporting schemes in different countries.

Overall, SWORD estimates suggest that the incidence of OHP in the UK might be slowly falling, from 2 per million workers for $1992-2000,{ }^{4} 1.5$ per million for $1996-2010$, to 1.2 per million for 2011-2015. A similar fall has also been noted for the 2000-2012 period for OA in the UK. ${ }^{8}$ Given the previously identified limitations of the SWORD reporting scheme in identifying trends in incidence, ${ }^{7}$ it is not possible to tell whether these changes reflect a true fall in disease incidence or an apparent fall relating to changes in reporting patterns. Of note, incidence data from primary care (1991-2003) and mortality data from the ONS (1968-2008) for all cause HP in the UK have not noted a significant fall. ${ }^{14} 15$ The annual incidence of all cause HP for the UK population has been estimated to be $\sim 9$ cases per million, which is clearly higher than our estimate for OHP. It is not possible to ascertain how much of the total HP burden is occupational however, as the degree of under-reporting of OHP is not known, and all cause HP includes the working and non-working population. This difference is however in keeping with published case series of all cause HP, where significant proportions related to domestic bird exposures. ${ }^{2}$

Over the period studied, the average age of reported cases of $\mathrm{OHP}$ in the UK was 52, which is similar to the 57-year-old mean reported for incident cases of all cause $\mathrm{HP}^{14}$ and the 48 -year-old average age for OHP noted in Spain ${ }^{10}$ and the Czech Republic, ${ }^{12}$ respectively. It is not possible to tell from the SWORD data why OHP most commonly affects workers in this age group, although possible contributing factors include long disease latency, delays in diagnosis, smoking cessation and temporal changes in workplace exposures, roles or health surveillance. Very little is known about the latent period in OHP, with the limited available Czech data suggesting that it varies widely in individuals, ranging between 0.2 and 40 years (median 12.5 years). ${ }^{12}$

OHP in the UK more commonly affects men than women, with about $80 \%$ of reported cases being men. This is in contrast
Figure 1 Suspected causes of OHP reported to SWORD 1996-2015 by the five-year time period. MWFs, metalworking fluids; OHP, occupational hypersensitivity pneumonitis.

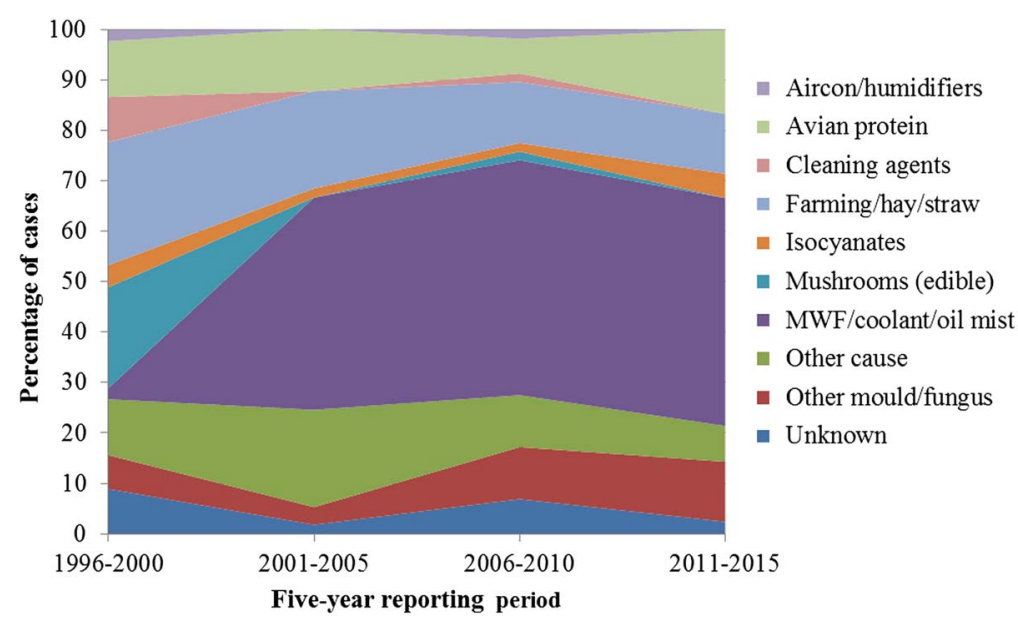


to the findings of a UK primary care study of all cause HP, which found an equal gender ratio. ${ }^{14}$ This male predominance is higher than that has been reported in other countries ${ }^{10-12}$ and is likely to reflect the demographics of the 'at risk' occupational groups. For example, data from 2008 recorded that $84 \%$ of farmers and $89 \%$ of metalworking machine operatives in the UK were men. ${ }^{16}$

Historically, the main occupations at risk of HP in the UK have been agricultural workers and bird handlers. ${ }^{4}$ Over the last 20 years, there has been a change in causation however, with an overall reduction in cases from agricultural exposures, particularly for mushroom workers. Possible explanations for this relate to improvements in working practices and an overall reduction in numbers of UK workers in these trades. In contrast to this fall, there has been a dramatic emergence of MWF-HP, from a single case reported in the 1996-2000 time period to $40-45 \%$ of all cases for the three more recent time periods. Although it is not possible to establish the reasons for this increase from the SWORD data, possible explanations include the increased use of water-soluble MWF, an increased number of cases found during outbreak investigations ${ }^{17} 18$ and an increased awareness among reporting clinicians. This temporal change in proportionate causation from the agricultural to metalworking sectors has not been noted in other European reporting schemes. ${ }^{12}{ }^{13}$ The majority of reported cases of MWF-HP have occurred in workers manufacturing components for cars and airplanes, as time-limited clusters of disease. ${ }^{17} \mathrm{OHP}$ may present in a number of ways, and clinicians should have a high index of suspicion not only when seeing symptomatic workers employed in these sectors, but also in any case of HP in a patient of working age where a detailed occupational and environmental history is warranted. Recognising OHP is important for an individual patient, but also has implications for other exposed coworkers, especially as outbreaks of disease have been reported. $^{18}$

Finally, in a small proportion of cases of OHP (overall 6\%), respiratory clinicians were not able to identify a suspected cause in the workplace. This stayed relatively stable over the study period and is in keeping with the 3\% figure reported from the Czech Republic. ${ }^{12}$ Continuing data collection through reporting schemes such as SWORD is important to help track temporal trends in incidence, to determine circumstances of exposure associated with a significant risk as well as to raise awareness of potential new causal agents.

In summary, this study has demonstrated that over the last 20 years, there has been a marked change in the causation of OHP in the UK, with MWF now being the most commonly suspected aetiological agent.

Acknowledgements The authors are grateful to all physicians who report to SWORD.

Contributors $C M B, M C$ and RA planned the study. CMB, REW and MC contributed to data collection and analysis. All authors contributed to the writing, revision and approval of the final manuscript.
Funding SWORD is supported by the Health and Safety Executive in Great Britain (contract number PRJ500).

Competing interests None declared.

Provenance and peer review Not commissioned; externally peer reviewed.

Open Access This is an Open Access article distributed in accordance with the Creative Commons Attribution Non Commercial (CC BY-NC 4.0) license, which permits others to distribute, remix, adapt, build upon this work non-commercially, and license their derivative works on different terms, provided the original work is properly cited and the use is non-commercial. See: http://creativecommons.org/ licenses/by-nc/4.0/

\section{REFERENCES}

1 Demedts M, Wells AU, Anto JM, et al. Interstitial lung diseases: an epidemiological overview. Eur Respir J Supp/ 2001;32:2s-16s.

2 Lacasse Y, Selman M, Costabel U, et al,. HP Study Group. Clinical diagnosis of hypersensitivity pneumonitis. Am J Respir Crit Care 2003;168:952-8.

3 Fernández Pérez ER, Swigris JJ, Forssén AV, et al. Identifying an inciting antigen is associated with improved survival in patients with chronic hypersensitivity pneumonitis. Chest 2013;144:1644-51.

4 McDonald JC, Chen Y, Zekveld C, et al. Incidence by occupation and industry of acute work related respiratory diseases in the UK, 1992-2001. Occup Environ Med 2005;62:836-42

5 Office for National Statistics Time Series: Employment release date, 16 March 2016. http://www.ons.gov.uk/employmentandlabourmarket/peopleinwork/employmentand employeetypes/timeseries/mgrz

6 Carder M, McNamee R, Turner $S$, et al. Improving estimates of specialist-diagnosed, work-related respiratory and skin disease. Occup Med 2011;61:33-9.

7 McNamee R, Carder M, Chen $Y$, et al. Measurement of trends in incidence of work-related skin and respiratory diseases, UK 1996-2005. Occup Environ Med 2008;65:808-14.

8 Stocks SJ, McNamee R, van der Molen HF, et al. Trends in incidence of occupational asthma, contact dermatitis, noise-induced hearing loss, carpal tunnel syndrome and upper limb musculoskeletal disorders in European countries from 2000 to 2012. Occup Environ Med 2015;72:294-303.

9 Elder D, Abramson M, Fish D, et al. Surveillance of Australian workplace Based Respiratory Events (SABRE): notifications for the first 3.5 years and validation of occupational asthma cases. Occup Med 2004;54:395-9.

10 Orriols R, Costa R, Albanell M, et al. Members of the Malaltia Ocupacional Respiratòria (MOR) Group. Reported occupational respiratory diseases in Catalonia. Occup Environ Med 2006;63:255-60.

11 Oksa P, Palo L, Saalo A, et al. Occupational diseases in Finland in 2012. New cases of recognized and suspected occupational diseases. Finnish Institute of Occupational Health, FIOH Bookstore, Topeliuksenkatu 41 a A, FI-00250 Helsinki, Finland.

12 Fenclová $Z$, Pelclová $D$, Urban $P$, et al. Occupational hypersensitivity pneumonitis reported to the Czech National Registry of Occupational Diseases in the period 1992-2005. Ind Health 2009;47:443-8.

13 Quirce S, Vandenplas O, Campo P, et al. Occupational hypersensitivity pneumonitis: an EAACI position paper. Allergy 2016;71:765-79.

14 Solaymani-Dodaran M, West J, Smith C, et al. Extrinsic allergic alveolitis: incidence and mortality in the general population. QJM 2007;100:233-7.

15 Hanley A, Hubbard RB, Navaratnam V. Mortality trends in asbestosis, extrinsic allergic alveolitis and sarcoidosis in England and Wales. Resp Med 2011;105:1373-9.

16 Office for National Statistics data. The sex gap: which jobs do men and women do. http://www.theguardian.com/news/datablog/2009/jun/03/gender (accessed Apr 2016).

17 Rosenman KD. Asthma, hypersensitivity pneumonitis and other respiratory diseases caused by metalworking fluids. Curr Opin Allergy Clin Immunol 2009;9:97-102.

18 Burton CM, Crook B, Scaife $H$, et al. Systematic review of respiratory outbreaks associated with exposure to water-based metalworking fluids. Ann Occup Hyg 2012;56:374-88. 